\title{
Raising or Lowering?-A Case Study of Alethic ACQ in Chinese and Southeast Asian Languages*
}

Gong Cheng

School of International Studies, Zhejiang University

Zhao-Hui Yi

Department of Asian Languages, Luoyang University of Foreign Languages

Jian-Guo Xiong

Department of Language Engineering, Luoyang University of Foreign Languages

\begin{abstract}
The present paper proposes a morphological lowering analysis for the structure associated with alethic ACQ, a postverbal morpheme capable of denoting the modality of ability and possibility in Chinese as well as many Southeast Asian languages. Built in the framework of distributed morphology, we suggest that ACQ is base-generated in a preverbal node as a modal element and lowers to a postverbal position during its derivation on the PF branch. We compare and contrast the proposed lowering account with the other model of analysis, the raising analysis, and demonstrate that the lowering account is superior both conceptually and empirically.
\end{abstract}

\section{Keywords}

alethic ACQ, distributed morphology, lowering, raising, Chinese, Southeast Asian languages

\footnotetext{
* An earlier version of this article was presented at the International Workshop on Typological Studies of Sinitic Languages, Zhejiang University, 2015. We thank Zhiming Bao, Walter Bisang, Danqing Liu, Stephen Matthews, Yicheng Wu and others for helpful comments. We are also grateful to anonymous SCL reviewers for interesting discussion and valuable comments. Needless to say, mistakes are all our own.
}

Studies in Chinese Linguistics, Volume 37, Number 2, 2016, 75-108 DOI: 10.1515/scl-2016-0004 (C)2016 by T.T. Ng Chinese Language Research Centre, Institute of Chinese Studies, The Chinese University of Hong Kong 


\section{Introduction}

In the genetically unrelated Mandarin Chinese and Southeast Asian languages (henceforth SEA languages), there is a somewhat peculiar morpheme with multiple functions and meanings, phonetically realized as de in Mandarin Chinese, duoc in Vietnamese, dai in Thai, daj in Lao, baan in Khmer, among many others. ${ }^{1}$ Following the practice of Enfield (2003), we label it "ACQ," based on its original

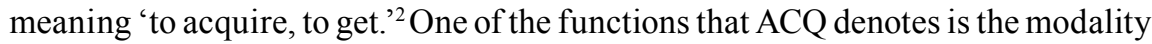
of ability or possibility in a postverbal position, translatable with 'can' or 'be able to,' as in the following sentences.
a. zhe zhong wenzhang ta xie de hao. this kind article he write ACQ well 'He can write this kind of articles well.'
b. khaw khian dai. he write ACQ 'He can write.' I come ACQ 'I can come.'
c. toi di duoc.
(Vietnamese)

The modality expressed by ACQ in (1) is called alethic by Cinque (1999: 78) and other researchers to denote a possibility or necessity independent of the speaker's deduction or opinion, contradicting epistemic and other modalities.

Over the past decades, a growing body of literature has been devoted to various aspects of ACQ, with prominent contributions from Bisang (1996), Enfield (2001, 2003), Simpson (2001), Wu (2009), among others. Their work has substantially improved our understanding of the element and provides a solid foundation for better theorizing.

The present study sets out to propose an alternative account that pertains to the derivation of the structure associated with ACQ. In particular, it attempts to solve a long-observed puzzle, namely, ACQ has many preverbal properties though it is linearly postverbal. The only study in existing literature addressing the problem, that of Simpson (2001), suggests that the structure is derived via predicate raising, which allows ACQ to appear in a postverbal position. We shall argue against such an analysis, and propose that it is a morphological lowering operation that puts ACQ in a surface postverbal position.

\footnotetext{
1 According to $\mathrm{Wu}$ (2009), this morpheme and its cognates are used in more than 30 languages and dialects in South China, mostly belonging to the Tai-Kadai, Miao and Yao, and Mon-Khmer groups. In mainland Southeast Asia, it is also observed in 16 languages that belong to the Tai, MonKhmer, Austronesian, and the Tibeto-Burman groups.

2 In the existing literature, it is also frequently notated as 'can' or simply de/DE.
} 
In what follows, we shall first present facts suggestive of ACQ's preverbal properties. Some other crucial facts will also be introduced. We then introduce the light predicate raising account proposed by Simpson (2001). In Section 4, we propose a morphological lowering account that is framed in the theory of distributed morphology (DM) as expounded in Halle and Marantz (1993, 1994) and subsequent work by them and many others. In Section 5, we make a detailed comparison between the two accounts, in an attempt to demonstrate the superiority of the proposed method. Section 6 concludes the paper.

\section{Facts and questions}

A careful examination of the relevant data made available in the existing literature seems to suggest that alethic ACQ, though postverbal in position, actually exhibits features that are high in the clausal structure instead of internal to VP.

The first clue comes from the use of ACQ as a modal element itself, since it is generally accepted that modality is a functional property rather than a lexical one. In almost all the linguistic theories, modals, together with other functional elements such as tense, aspect, focus, etc., are represented at a position outside VP. In his influential work, Cinque (1999) proposes a universal hierarchy of functional heads, a simplified version of which is provided by Simpson (2001:93) as follows:

(2) epistemic modals $>$ tense $>$ deontic modals $>$ alethic modals $>$ aspectuals $>$ VP

If Cinque is right, there is a reason to believe that alethic ACQ should be structurally higher than VP.

It should be noted that in languages that make use of ACQ, there is also a set of free modal verbs that invariably take a preverbal position, as in the following sentences.

(3) Chinese:

a. zhezhong wenzhang wo neng xie hao. this-kind article I can write well 'I can write this kind of articles well.'

b. zhezhong wenzhang wo xie de hao. this-kind article I write ACQ well 'I can write this kind of articles well.'

(4) Thai:
a. khaw khuuan maa.
b. khaw maa dai. he should come 'He should come.' he come ACQ 'He can come.'

(5) Cambodian: (from Simpson 2001)
a. k'nyom dtrou jaak-jeun.
I must leave
'I must leave.'
b. goa'at root-ut baan. he run ACQ 'He can run.' 
(6) Vietnamese: (from Simpson 2001)
a. toi phai di mua cam.
I must go buy orange
b. anh-ta den duoc.
'I must go and buy oranges.'
he come ACQ
'He can come.'

Examples in (3)-(6) show that two devices are adopted to express modality in the languages under investigation: preverbal modal verbs and postverbal ACQ. Given the general pattern in these languages, a postverbal position is obviously exceptional for modals.

A closely related fact is that ACQ can co-occur with a preverbal modal verb, as shown below.

(7) wo keyi kan de qing heiban shang de zi. I can see ACQ clear blackboard Loc. Mod. words 'I can see the words on the blackboard.'

(8) khaw naa-ca pen pheuan kan dai. they should are friends together ACQ

'It should be the case that they can become friends.'

(9) laaw saa-maat vaw phaasaa laaw daj boo? he can speak language Lao ACQ Q

'Can he speak Lao?'

An interesting observation at this juncture is that preverbal positions allow multiple modalities, including epistemic as in (4a) and deontic as in (5a)-(6a), whereas ACQ is associated only with alethic modality. This fact has not yet received a proper treatment. We would come back to it in Section 5.3.

The second clue that ACQ is associated with preverbal properties comes from negation. That is, the negation marker is placed before ACQ rather than before the main verb:

(10) ta qu $b u$ de, wo ye qu $b u$ de.

(Chinese)

he go not ACQ, I too go not ACQ

'He cannot go, neither can I.'

(11) khaw phuut phasaa thai mai dai. he speak language Thai not ACQ

'He cannot speak Thai.'

(12) kñom dtəu $\min$ baan.

(Cambodian)

I go not ACQ

'I cannot go.' 
(13) law vaw phaasaa law bo daj.

he speak language Laos not ACQ

'He cannot speak Lao.'

The invariable occurrence of the negation marker prior to ACQ instead of the main verb provides another clue that ACQ is likely base-generated in a position higher than VP, since it is generally accepted that negation applies at the clausal level, rather than inside VP (see, for instance, Pollock 1989). Huang (1988: 284) specifically proposes a principle for Chinese that requires the negative morpheme $b u$ to form an immediate construction with the first $\mathrm{V}^{0}$ element following it. If Huang is right, then ACQ is the first verbal element in the Chinese examples in (10), and, by extension, in the cognate Thai, Cambodian, and Lao instances of (11)-(13) as well.

The last clue is that ACQ is obligatorily used when a speaker responds affirmatively to a yes-no question, as illustrated in (14)-(15). Note that a crosslinguistic variation is observed here, namely, ACQ must co-occur with the verb in Chinese, whereas it can be used alone in SEA languages:

: Zhe ge dongxi ni na de dong ma?

This CL thing you take ACQ move Q

'Can you move this thing?'

$\begin{array}{ccc}\text { A1: Na de dong. } & \text { A2: } \\ \text { take ACQmoldong. } & \text { A3: } & * \text { de. } \\ \text { take/move } & & \text { ACQ }\end{array}$

(Chinese)

(15) Q: khaw phuut phasaa thai dai mai?

he speak language Thai ACQQ?

'Can he speak Thai?'
A1: phuutdai.
speak ACQ
A2: *phuut.
A3: dai.
speak
ACQ
'He can.'

As pointed out in Simpson (2001), the above examples suggest that ACQ is a clausal element rather than a VP-internal one, since yes-no questions are answered with the highest verbal element in the sentence, along the same line as the negation facts that we discussed earlier. As to the difference in whether ACQ alone suffices as an answer, we assume it as stemming from a cross-linguistic variation in morphological properties, a point which we will return to in Section 5.2.

In view of the aforementioned facts, it seems quite evident that alethic ACQ has properties that are typical of elements higher than VP: its modal use, its adjacency to the negation marker, and its obligatory use in responding to simple yes-no questions. We believe that what we see here is a phenomenon commonly 
designated as a "form-meaning mismatch." If so, a legitimate research question naturally arises, namely, how should we best capture the paradoxical phenomenon that alethic ACQ is linearly postverbal but exhibits preverbal properties?

In the present theoretical framework, it seems difficult to account for this form-meaning mismatch by assuming that ACQ is base-generated in a postverbal position. One such account can be found in Sybesma (2008), which is in fact a comprehensive analysis of various interpretations associated with the element. Keeping to the alethic meaning and omitting some details that are not directly relevant, the structure that Sybesma proposes is as follows: ${ }^{3}$

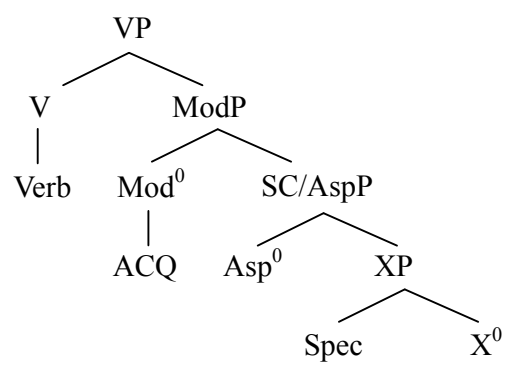

In (16), ACQ is treated as a modal verb; to its left is a telic verb, and to its right is a resultative expression that indicates the end point of the action denoted by the verb, and the alethic interpretation emerges when ACQ combines with a telic predicate. Sybesma accounts for the relevant data with this structure in the following way: first, ACQ occurs after the verb because it is base-generated postverbally, second, ACQ has a modal use because it occupies the modality node in the small clause occurring immediately below the main clause verb.

Sybesma's account, however, leaves a number of important questions unanswered. First, free modal verbs are base-generated in a preverbal position and ACQ in a postverbal position in his system. How does it come to pass that modals are split into two positions? Second, if ACQ is structurally lower than the main verb, how should the data related to negation and simple questions be accounted for? Sybesma does not directly address these issues, so we have reason to doubt that his account can provide an adequate answer to these and other questions.

If the accounts assuming a base-generated postverbal position for ACQ prove incapable of explaining the puzzling behavior of alethic ACQ, an available alternative in generative grammar is to resort to movement, that is, to have ACQ base-generated at a preverbal position and end up in a surface postverbal position via some movement operation(s). We believe this movement approach is viable and adopt it without further argument.

3 "SC" in (16) stands for a small clause. 
Assuming that the movement approach is on the right track, we are confronted with two options: raising or lowering. In the context of the present discussion, raising means to move the VP up so that ACQ appears in a postverbal position as a consequence; lowering, on the other hand, means to move ACQ from a preverbal position to somewhere inside the VP.

The choice of whether the movement should be raising or lowering is not an easy decision, since it is associated with a host of underlying assumptions. If the relevant phenomenon is taken to be syntactic in nature, then raising is the only option, since syntactic movements are constrained by locality conditions, like the head movement condition, in such a way that the moved element, technically called an antecedent, c-commands its copy, previously known as trace. This c-command requirement can be met only if the moved element climbs up the structure. ${ }^{4} \mathrm{~A}$ consequence of the locality constraints is that if a lowering operation is to be applied, one has to prove that it is not syntactic, therefore free from conditions on syntactic movement.

Before leaving this section, we believe that it is necessary to present another fact related to alethic ACQ that any account has to deal with. That is, in most Sinitic languages and dialects, or languages heavily influenced by Chinese, ACQ can only be adjacent to the verb. Thus, in case the verb takes an object (O) as its complement, the basic word order is "V + ACQ + O", while "V + O + ACQ" sequence is generally unacceptable (see, for instance, Huang and Liao 1991 for details). This fact is illustrated below:
a. ta chuli de hao zhejian shi.
he handle ACQ well this-CL matter
'He can handle this matter properly.'
b. *ta chuli hao zhejian shi de.
he handle well this-CL matter ACQ
'He can handle this matter properly.'

(18) a. wo da de guo ta.

I fight ACQ over him

(Chinese)

'I can fight and defeat him.'
b. *wo da ta de guo. ${ }^{5}$
I fight him ACQ over
'I can fight and defeat him.'

(Chinese) 
c. *wo da guo ta de.
I fight over him ACQ
'I can fight and defeat him.'

By contrast, in most SEA languages, the typical word order is "V + O + ACQ", while "V + ACQ + O" is acceptable under more restricted circumstances:

(19) a. khaw phuut phasaa thai dai.

He speak language Thai ACQ

'He can speak Thai.'

b. khaw phuut dai laai phasaa.

he speak ACQ many languages

'He can speak many languages.'

(20) a. ong-ai noi tieng-anh duoc.

(Vietnamese, Simpson 2001:112)

he speak English ACQ

'He can speak English.'

b. ong-ai noi duoc tieng-anh.

He speak ACQ English

'He can speak English.'

(21) a. man set thuaj loon daj.

she wipe bowls clean ACQ

'She can wipe the bowls clean.'

b. man tii pet too nan taaj daj.

she beat duck CL that die ACQ

'She can beat that duck to death.'

As observed by Simpson (2001), different word orders may, to varying degrees, be associated with variations in discourse focus. For instance, in Thai it is always the clause-final constituent that receives the focus interpretation. Thus ACQ gets focused as in (19a), while the clause-final object laai phasaa "many languages" becomes the focus of the discourse as in (19b). This contrast still obtains in the Vietnamese instances like (20), but to a much less salient degree. However, a "V $+\mathrm{ACQ}+\mathrm{O}$ " sequence is generally banned in Sinitic languages. There are some languages and dialects in South China that allow such a sequence, however, they do not normally allow the clause-final object to serve as the focus of the discourse. A Cantonese instance below is cited by Simpson (2001) to show that the object can be an indefinite and nonreferential part of verb-object idiom sequences, thus cannot possibly be available for focusing. 
(22) keoi m jau dak seoi.

he Neg travel ACQ water

'He can't swim.'

We would return to the focus facts in Section 5.2.

To sum up this section, we first introduced data suggesting that alethic ACQ manifests a certain form-meaning mismatch in that it is linearly postverbal, but is associated with clausal rather than VP-internal properties. We also presented an additional fact important for any theory pertinent to ACQ: variation in the relative word order between ACQ and the object of the predicate. In other words, we take the following list as the core facts that need to be accounted for in the analysis of ACQ in Chinese and SEA languages:

(23) a. Its use as a modal, and relatedly, its ability to co-occur with a preverbal modal

b. Its ability to take negation

c. Its obligatory use in answering simple questions

d. Variation in word order between Mandarin Chinese on the one hand and SEA languages on the other.

In the following sections, we proceed to an examination of how to develop an optimal account of these facts.

\section{The raising analysis}

Taking the behavior of dai in Thai as central data, Simpson (2001) develops a syntactic movement account for properties of alethic $\mathrm{ACQ}$ for a number of languages and dialects. In his account, ACQ is treated as a modal verb, which projects its own phrase, notated as DeP, which, in turn, takes a VP as its complement, and the main clause subject as its specifier:

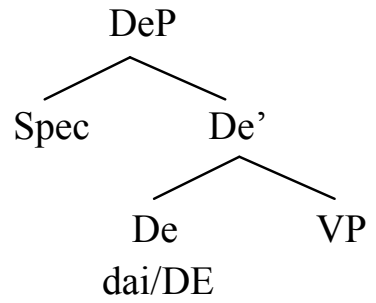

Simpson relies heavily on information structure in his account. He believes that in clauses with ACQ, the VP predicate represents presupposed old information while the new/focused information is the affirmation of the positive (or negative) possibility of the content of the predicate. The VP predicate is therefore "light," 
capable of raising, leaving the clause-final position to the focused element. For this reason, he dubs his account Light Predicate Raising.

In Simpson's account, different structures and derivations are suggested for the "V + O + ACQ" and "V+ ACQ + O" sequences, respectively. For the dominant "V + O + ACQ" structure in Thai, Simpson proposes that the predicate VP leaves DeP in order to "defocus" itself, and moves higher into the syntactic structure, so that ACQ gets focused in the clause-final position. He seems unsure about where the moved VP lands, so he vaguely notates it as the specifier of a certain XP, located between TP and DeP, as shown below:
a. khaw phuut phasaa thai dai.
He speak language Thai ACQ
'He can speak Thai.'

b.

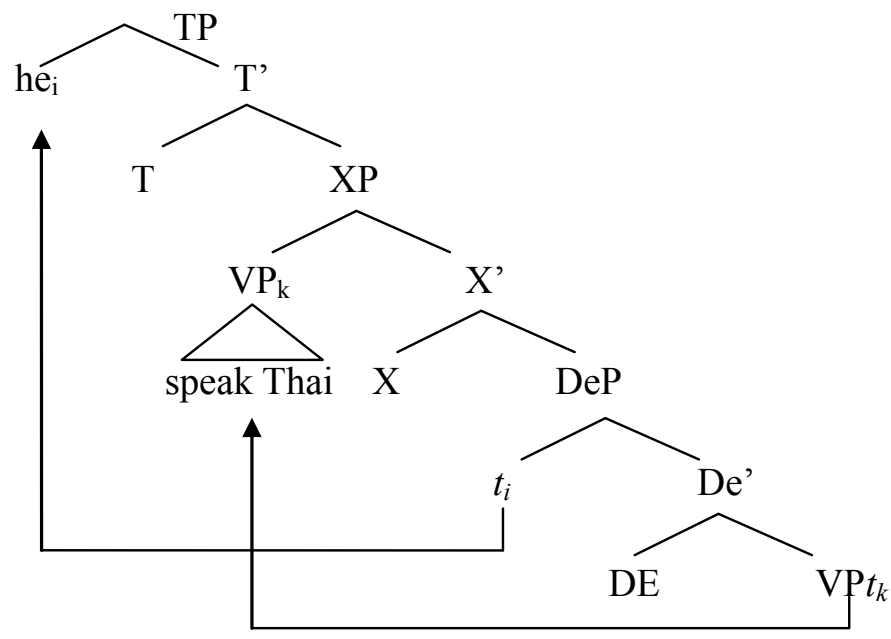

For the "V + ACQ + O" sequence, Simpson assumes that ACQ selects for a focus projection as its complement, a focused object moves to the specifier of this focus phrase, and the VP raises to an even higher position, the specifier of a certain YP. Thus, in Thai, in a sentence meaning 'he can speak many languages' as in example (19b), the object "many languages" moves to [Spec, FocP], and the rest of the predicate, in an operation similar to remnant movement in German, raises up to [Spec, YP]. The derivation is shown below in (26).

(26) a. khaw phuut dai laai phasaa. he speak ACQ many language 'He can speak many languages.' 
b.

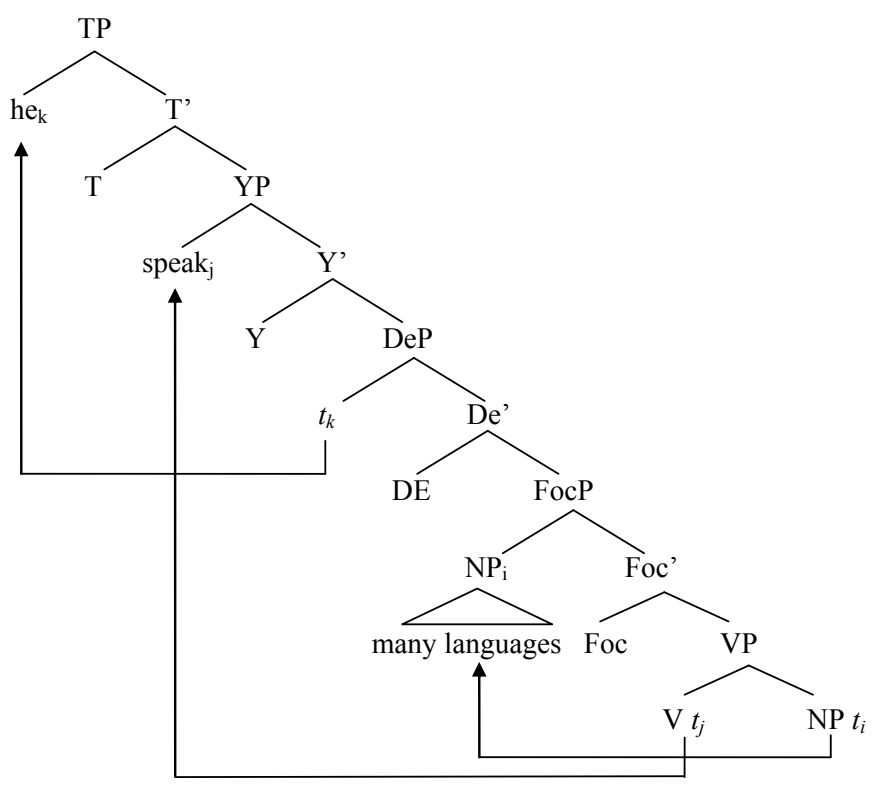

To sum up, Simpson's (2001) account is essentially based on the assumption that the predicate in ACQ-clauses is light since it represents presupposed old information whereas the clause-final position represents the new/focused information, the predicate is therefore required to raise in order to defocus itself. There are two structures and derivations, respectively for the "V + O + ACQ" and "V + ACQ + $\mathrm{O}$ " sequences. For the former, the predicate simply moves to a preverbal position, somewhere between TP and VP; for the latter, the object moves to the specifier of a FocP subcategorized by ACQ. The rest of the predicate undergoes a separate remnant movement to a preverbal position.

We believe that Simpson (2001) has made a valuable contribution to the topic at hand. Moreover, as it will become apparent in the subsequent sections, we share many of his assumptions even though we disagree on others. Nevertheless, we find his account unsatisfactory at places, which we shall discuss in some detail in Section 5, where a comparison and contrast is to be made between his account and ours.

\section{A proposed lowering account}

This section is devoted to explicating an alternative account that attempts to derive the core properties of the alethic ACQ via a morphological lowering operation. We first lay out its theoretical framework, then outline the derivation, and finally focus on the key assumption of our proposal concerning morphological properties of ACQ in the languages under discussion. 


\subsection{The theoretical framework}

Most practicing generative linguists are reluctant to adopt lowering movement, since, as mentioned in Section 2, movement has long been regarded as a syntactic operation tightly regulated by locality constraints, so that all known types of syntactic movement are taken as raising. However, distributed morphology (DM) (Halle and Marantz, 1993, 1994), a new architecture of grammatical theory, argues that, alongside syntactic movements, there exist morphological movement operations as well that occur after the syntactic derivation, in the PF branch. One such operation is referred to as lowering, which unites syntactic terminals that are phonologically spelled together but not joined by syntactic operations such as raising, schematized below (see Embick and Noyer 2001: 561):

$$
\begin{aligned}
& \mathrm{X}^{0} \text { lowering onto } \mathrm{Y}^{0} \\
& {\left[{ }_{\mathrm{XP}} \mathrm{X}^{0} \ldots\left[{ }_{\mathrm{YP}} \mathrm{Y}^{0} \ldots\right]\right] \rightarrow\left[{ }_{\mathrm{XP}} \ldots\left[{ }_{\mathrm{YP}} \ldots\left[{ }_{\mathrm{Y}}{ }^{0} \mathrm{Y}^{0}+\mathrm{X}^{0}\right] \ldots\right]\right]}
\end{aligned}
$$

Taking English as an example, t(ense) is not attached to the verb $\mathrm{V}$ in syntax, instead it resides in a position higher than $\mathrm{V}$. That is why in negative sentences with $d o$-support, $\mathrm{T}$ is higher in structure than $\mathrm{V}$, as shown in (28a) below. But in affirmative sentences, $\mathrm{T}$ surfaces on $\mathrm{V}$ via the lowering operation, as in (28b):
a. Mary $\left[{ }_{T P}\right.$ didn't $\left[{ }_{v \mathrm{P}}\right.$ loudly play the trumpet] $]$
Negative
b. Mary $\left[_{T P}[\right.$ [ loudly play-ed the trumpet $\left.]\right]$
Affirmative

The coexistence of syntactic movement (raising) and morphological movement (lowering) is made possible in DM since, contrary to the lexicalist tradition, it abandons the presyntactic lexicon, which is supposed to build words that feed syntax in their fully-inflected forms. Instead, syntactic operations in DM start with atomic building blocks, morphemes, or more accurately, abstract feature bundles that denote terminal elements in syntactic or morphosyntactic representations. Such abstract morphemes do not have phonological features, which are supplied at the postsyntactic stage of derivation by a list called Vocabulary, in accordance with a hypothesis known as late insertion (see, for instance, Halle and Marantz 1994). A related tenet in DM is that morphology, traditionally understood as residing in the lexicon, is distributed into two major components of grammar. The first component is simply syntax, or, more accurately, overt syntax, where syntactic rules assemble and manipulate the collection of morphemes into a hierarchical structure. The second component, morphology, is a series of operations that occur on the PF branch following the point at which the syntactic derivation splits between PF and LF. Such operations are responsible for providing terminals with phonological information, fixing their linear order, and carrying out further computations in line with conditions or requirements from universal grammar (UG) and individual grammar(s) so that the expressions thus derived can be (fully) interpreted at PF. This DM scheme is illustrated in (29). 
LISTS ACCESSED

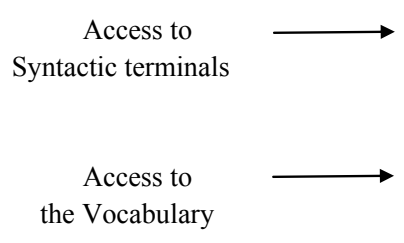

\section{STAGES OF THE DERIVATION}

Syntactic derivation

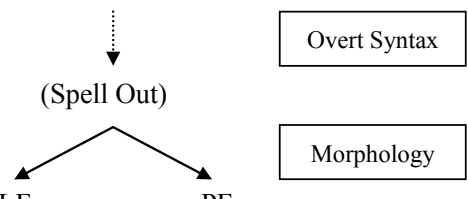

Lowering is believed to possess three important properties. First, the adjoined heads do not have to be linearly adjacent. For example, in (28b), lowering of $\mathrm{T}$ is not blocked by the intervening adverb loudly. Second, lowering in morphology follows the application of syntactic operations, which may remove the environment for lowering. By contrast, the opposite can never hold. Therefore, in (28a) "Mary did not loudly play the trumpet", negation, a syntactic operation, blocks lowering from taking place. Third, lowering observes the relativized minimality constraint $(\mathrm{RMC})$ in a reverse order. Simply put, if an overt head $\mathrm{Z}^{0}$ intervenes between $\mathrm{X}^{0}$ and $\mathrm{Y}^{0}, \mathrm{X}^{0}$ cannot lower down to $\mathrm{Y}^{0}$ (see Myler 2009):

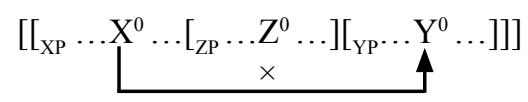

An anonymous reviewer asks whether it is contradictory for the morphological operation of lowering to observe the RMC, which is originally conceived as a syntactic constraint (see Rizzi 1990). However, the constraint is reformulated in the more recent minimalist program as an economy condition that guarantees efficient computation, one of the so-called third factors (Chomsky 2005), which, in turn, are considered to be not language-specific, but rather general biological and human-specific factors that play some explanatory role behind language. It is in this sense that we believe RMC is more appropriately regarded as a condition imposed by the sensorimotor (SM) and conceptual-intentional (C-I) interfaces, and as such is observed in both syntactic and morphological operations.

To recap, in the framework of DM, morphological movement is available alongside syntactic movement, with different properties. Syntactic movement can only be raising, in the leftward direction, whereas morphological movement can be lowering in a rightward direction; syntactic movement applies at an early stage in the derivation, whereas morphological movement is postsyntactic; syntactic movement observes RMC from right to left, and morphological movement observes this constraint from left to right.

\subsection{Derivation of the alethic ACQ-clauses}

In the spirit of DM, what we propose for the derivation of the ACQ-clauses consists of two major parts: syntactic and morphological. The former refers to the structure built from syntactic terminals in overt syntax, as indicated in (28). We hold the same 
assumption as Simpson (2001) that, as a modal element, ACQ is base-generated above VP, in accordance with Cinque's (1999) hierarchy as indicated in (2) and relevant empirical facts discussed in the first section. We notate it as the $\mathrm{Al}($ ethic) node, rather than the more language-particular de node in Simpson's system. Al projects onto an alethic phrase AlP, taking $v \mathrm{P}$ as its complement. In overt syntax, that is, prior to Spell-Out (SO), the subject inside VP moves to [Spec, AlP].

Another crucial assumption that we make is that ACQ is morphosyntactically a clitic in essential aspects, since it clearly meets Boskovic's (2002: 329) definition of clitics "as nonbranching elements (i.e., ambiguous $\mathrm{X}^{0} / \mathrm{XPs}$ ), as suggested in Chomsky 1995a." A more detailed discussion of the issue will be given in the following subsection. For ease of exposition, we designate the $\mathrm{X}^{0}$ variety of ACQ an affix and the XP variety a clitic, in keeping with the more traditional practice.

After SO, the structure assembled by syntax enters into the morphological component on its way to PF, where we assume that ACQ undergoes lowering as a clitic. We recognize two varieties here. By the first, which is called affixation, ACQ lowers as an $\mathrm{X}^{0}$ and adjoins to the closest verbal element, giving rise to the " $\mathrm{V}+$ ACQ + O" sequence, shown below: ${ }^{6}$

(31) ACQ-affixation

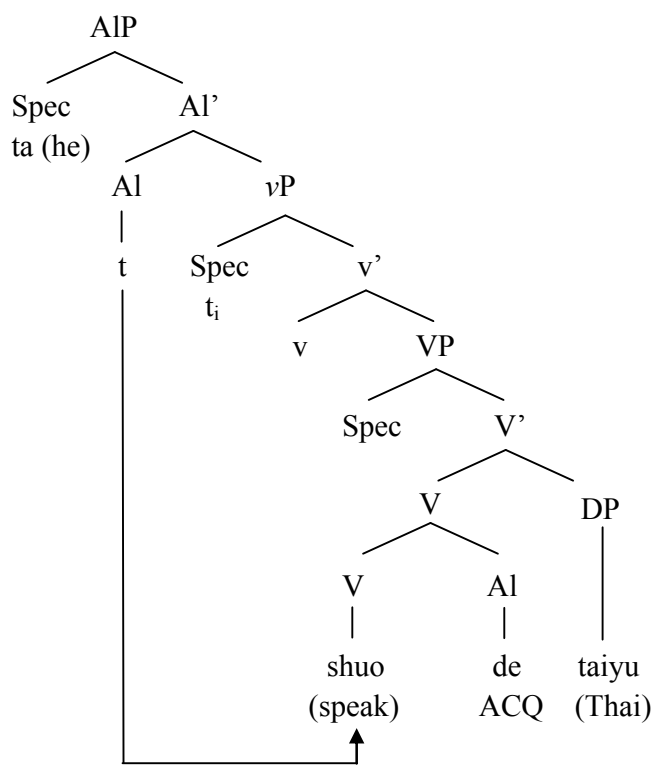

${ }^{6}$ In this and subsequent diagrams, we follow a frequently adopted practice of using a superscripted bar (') to represent an intermediate projection, and a t(race) to represent the original place of a moved element, with the understanding that they are just for illustration purposes, without any theoretical implication. 
The second variety of the lowering operation is cliticization, by which ACQ lowers as an XP and adjoins to the closest VP, yielding the "V + O +ACQ" sequence, as in (32) below:

(32) ACQ-cliticization

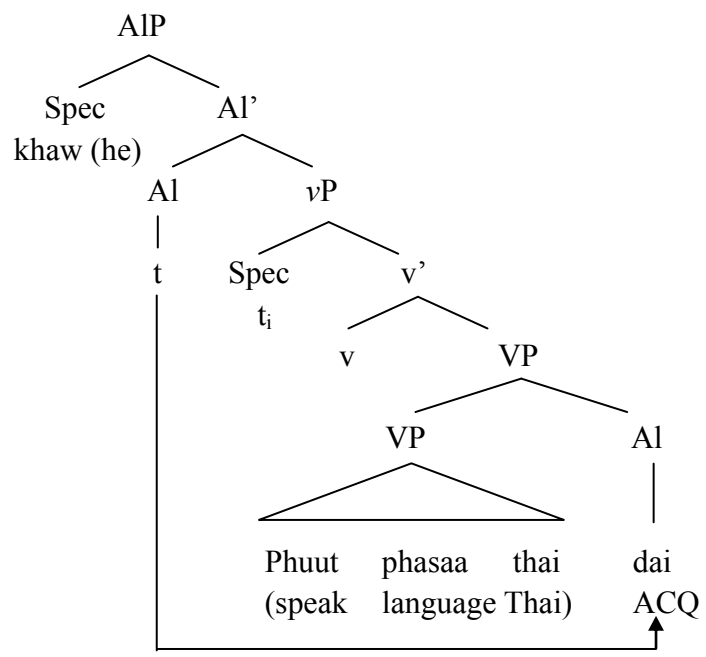

(31) is intended to accommodate facts from Mandarin Chinese and, to a somewhat lesser extent, most other Sinitic languages. ${ }^{7}$ (32), on the other hand, captures what we perceive as true of the element in SEA languages.

In a nutshell, ACQ in our proposed account is generated above $\nu \mathrm{P} / \mathrm{VP}$, at the Alethic modal node. It projects its phrase notated as AlP, with $v \mathrm{P}$ as its complement. In the postsyntactic stage, $\mathrm{ACQ}$, as an ambiguous $\mathrm{X}^{0} / \mathrm{XP}$, lowers down to inside $\mathrm{VP}$, adjoining either to $\mathrm{V}$ via affixation or to VP via cliticization. As a result, ACQ becomes postverbal in linear order.

\subsection{Morphological properties of ACQ}

In the proposed account, a crucial assumption is made that ACQ is an affix in Mandarin Chinese and most other Sinitic languages, whereas it counts as a clitic in SEA languages. In this section, we present evidence in support of the assumption, primarily by examining the morphological properties of the morpheme. We shall endeavor to prove that this assumption is solidly built on the historical development of ACQ, and may even be said to be a reconstruction of the diachronic changes in ACQ's morphological properties over the past millennia.

\footnotetext{
7 It is widely observed that Sinitic languages in South China are in the middle of the continuum between the two extremes of Mandarin Chinese and SEA languages in this aspect (see Wu 2003 and references therein for details).
} 
We start with the Chinese data, where ACQ is generally believed to originate. Based on an enormous amount of ongoing research, we believe that there are three distinct stages in the change of the morpho-syntactic properties of the element, as outlined below.

Stage I. Preverbal Content Word. It is a generally accepted observation that ACQ in Old Chinese (between 500 B.C. and 200 A.D.) was a content word that behaved no differently from other morphemes of the same kind, both in word order and in phonology. Its basic meaning was 'to acquire, to obtain.' Example (33) below from The Book of Changes, where ACQ 'to acquire' contrasts with shi 'to lose,' illustrates its use as a lexical verb:

西南 得 朋, 東北 坒 朋
xinan de peng, dongbei sang peng.
southwest acquire friend, northeast lose friend
'Acquire friends in southwest and lose friends in northeast.'

In addition, ACQ at the stage was equipped with modal meanings as well, consisting of two subtypes. One is deontic modality denoting the speaker's attitudes, as shown by the following example from Intrigues of the Warring States: Yan III:

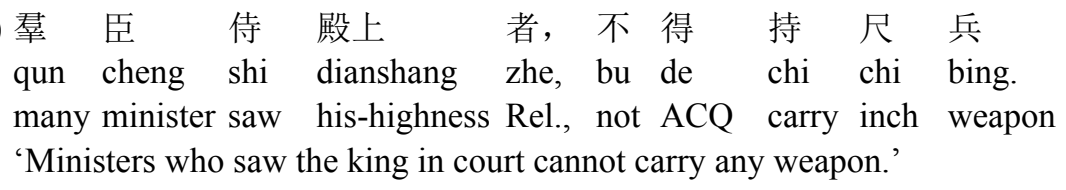

These two functions, one to denote the lexical meaning of "to acquire, get", and the other the deontic modality, are kept intact in Modern Chinese, as shown below: ${ }^{8}$

(35) a. wo de le yibi jiangjin.

I get ASP a prize

'I got a prize.'

b. zhege mimi, ni bu de gaosu bieren.

this secret, you not ACQ tell other

'You must not tell this secret to others.'

The other subtype of modal meaning that ACQ had at the time was alethic. Example (36), from The Analects of Confucius, provides a concrete instance.

(36) 子曰: “里仁爲 美。

$\mathrm{Zi}$ yue: 'li ren wei mei.

'Confucius say live-in benevolence is good.'

${ }^{8}$ Note that $d e$ with these preverbal uses carries the rising tone (the second tone), in contrast to the postverbal de, which is toneless. 
$\begin{array}{llllll}\text { 擇 } & \text { 不 } & \text { 處 } & \text { 仁, } & \text { 焉 得 知? } \\ \text { ze } & \text { bu } & \text { chu } & \text { ren, } & \text { yan de } & \text { zhi? } \\ \text { choose not } & \text { live-in benevolence, } & \text { how } & \text { ACQ } & \text { know }\end{array}$

'Confucius said: it is good to live in benevolence. If one does not choose to live in benevolence, how can one be wise?'

As can be seen clearly from these examples, ACQ in Old Chinese is preverbal in word order, and is associated with both lexical and modal meanings, a scenario summarized by Sun (1998:109) as follows:

In Old Chinese the dominant use of DE was as a full lexical verb, a free lexical morpheme. At the same time, it was also commonly used as a modal auxiliary in the DE V sequence, which was perhaps the first step in the long journey toward cliticizing around the verb.

As a matter of fact, preverbal modal use of ACQ similar to (36) can still be found in many dialects of Modern Chinese, though not in Mandarin Chinese itself, especially in negation or interrogative sentences. ${ }^{9}$ The following instances are from Jianghuai Mandarin, the native tongue of one of the authors:

(37) a. jinge ge de xia yu?

today Q ACQ fall rain

'Can it rain today?'

b. jinge xia-yu, ta bu de lai le.

today fall-rain, he not ACQ come Exc.

'It is raining today, (so) he is unable to come.'

Stage II. Postverbal Functional Word. In Middle Chinese (between A.D. 2011000), some major changes occurred to ACQ. The most noticeable change is that the dominant word order of "ACQ V" in Old Chinese practically disappeared, giving way to a "V ACQ" ordering. In other words, ACQ has shifted from predominantly a preverbal position to a postverbal one. With the shift, the preverbal ACQ could only denote the activity sense 'to acquire' whereas the alethic modality became available only postverbally. The next example from Lunheng by Wang Chong of the East Han Dynasty is such an instance, also cited in Simpson (2001):

$\begin{array}{lll}\text { (38) - } & \text { 人 撃 得 } \\ \text { yi } & \text { ren ji de. } \\ \text { one } & \text { person play ACQ } \\ \text { 'One person can play (it).' }\end{array}$

9 We thank Danqing Liu (personal communication) for bringing this point to our attention. 
Needless to say, this shift may plausibly be interpreted as a piece of strong evidence in favor of the proposed lowering account.

Note that ACQ at the stage is not fixed in position, in that it does not have to be attached to a verbal element. (39) below from Hanshu (The History of the Han Dynasty), written in the same period as Lunheng, is frequently cited as evidence for positional mobility, since it is separate from the verbal element in the clause, rather than attached to it.

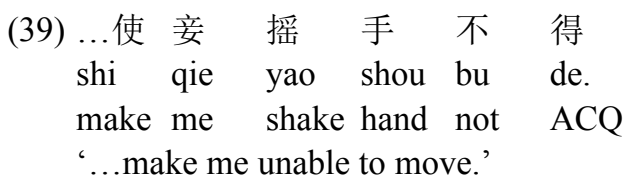

Other changes that accompanied the shift from "ACQ V" to "V ACQ" word order include the emergence of some other functions that are typical of grammatical words, such as indicating perfection and completion, which we discuss in conjunction with ACQ in SEA languages shortly below.

Stage III. Affix. From the late Middle Chinese (A.D. 1001) on to the present, ACQ continued to move along the grammatical cline, and by an incremental process, eventually began to behave as an affix, which is manifest in many a facet. Keeping to those facets immediately related the alethic ACQ, the most prominent change seems to be phonological attrition and the accompanying fixation of word order. The postverbal ACQ, previously pronounced as /tək/ in Middle Chinese, is further depleted to a schwa vowel and a neutral tone, due largely to a general loss of the word-final glottal stop around the 13th century (see Dong 1966). As a result, ACQ came to be pronounced as /ta/, which has persisted until today. As a consequence, its word order became highly rigid, the "V + O + (not) ACQ" order as in (39) was taken over by the "V + (not) ACQ $+\mathrm{O}$ " order, which is its only permissible order in Mandarin Chinese. Such a change is again aptly put by Sun (1998: 132) as follows: "(T)he DE in the V-DE $\mathrm{V}$ form has shown a higher degree of selection than the DE in the DE V form, in the sense that it must follow a verb immediately. Therefore, it behaves more like an affix than a clitic."

We hope that the foregoing discussion, though sketchy, is adequate in establishing the fact that ACQ in Chinese underwent three stages of historical development: from a content morpheme in Old Chinese, to a postverbal functional word in Middle Chinese, and ends as an affix in Mandarin Chinese.

Having discussed the morphological properties of ACQ in Chinese, we now turn our attention to its cognates in SEA languages. It has long been suggested that ACQ was adopted first by Tai people who originally inhabited parts of Southeast China and later emigrated to Modern Thailand and other parts of mainland Southeast Asia around the 11th and 12th centuries (see, for instance, Simpson 2001, Enfield 
2003, Wu 2009). To our minds, this proposition is almost indisputable since ACQ in SEA languages share a whole array of features with that in Middle Chinese.

In the first place, they have the same spectrum of functions and meanings. Those of ACQ in SEA languages are summarized by $\mathrm{Wu}(2009: 196)$ as follows (also see Enfield 2003: 42 for a similar list):

(40) a. A main verb

b. A marker of perfective aspect

c. An alethic postverb

d. A marker of a stative/extent complementation

e. A marker of an alethic complement clause

We keep to the postverbal functions and meanings (40b-e) here, and make a pointby-point comparison.

First, (40b), a marker of perfective aspect, namely, ACQ in SEA languages can mark the successful completion of an event. This function is also extensively documented for ACQ of Middle Chinese, though has disappeared in Mandarin Chinese. The following examples illustrate this point.

(41) a. Vietnamese (Enfield 2003): duoc

chet duoc ba ngnoi.

die Perf. three person

'Three people have died.'

b. Middle Chinese (Yu Xin Yuan Shi 'The Poem of an Embittered Wife')

嫁 得 長安 少年

Jia de Chang'an shaonian.

marry Perf. Chang'an young-man

'Got married to a young man in Chang'an.'

Second, (40c), an alethic postverb, that is, a V ACQ sequence that denotes possibility or permission. Like the case of the perfective marker, this function of ACQ in SEA languages was also common in Middle Chinese, but is no longer available in Mandarin Chinese.

(42) a. Thai: dai

khog ni kin dai.

thing this eat ACQ

'The thing can be eaten (the thing is edible).'

b. Middle Chinese (Hanshanzi Shiji 'Collection of Poems by Hanshanzi')

粫猴 尚教 得

mihou shang jiao de.

monkey even teach ACQ

'Even a monkey can be taught.' 
Third, (40d), marker of a stative/extent complementation, that is, to introduce a stative/ extent complement clause.

(43) a. Vietnamese (Enfield 2003)

Anh a'y chay duoc nhanh lam.

man that run ACQ fast very

'That man ran very fast.'

b. Middle Chinese (Zhuzi Yulei)

若 讀 得 熟, 而又 思 得 精......

ruo du de shu, er you si de jing ......

if read ACQ careful, and then think ACQ deep

'If (one) read carefully and then think deeply.....'

The last of the functions that the two languages share - a marker of an alethic complement clause - has been abundantly demonstrated in previous sections. Note that in both types of languages, this function is associated with a certain degree of positional freedom, whereby "V O ACQ" and "V ACQ O" sequences are both allowed.

Moreover, ACQ in SEA languages share yet another feature with Middle Chinese but not Modern Chinese, that is, its ability to be used alone when responding to yes-no questions (see (15)). The Middle Chinese example below, from Wudeng Huiyuan of Song Dynasty, illustrates the point:

(44) 師 曰: “問 一段 義 得 麼?” 曰: “得。”

shi yue: wen yi-duan yi de mo? yue: de

masteraid: sask a-CL sutra ACQ Q? said: ACQ

'The master asked: "can I ask about a piece of the sutra?" (he) answered: "yes".'

Unsurprisingly, new functions added to ACQ in Modern Chinese are notably missing in its cognates of the SEA languages, as they are in its predecessor in Middle Chinese. ${ }^{10}$ For instance, the ability to mark extent/degree in a causative context is unique to Modern Chinese, but unattested in both Middle Chinese and SEA languages (see, among others, Enfield 2003: 267-272, Wu 2009: 206, for some insightful discussion). The following examples from Huang (1988: 294) illustrate such a use.

(45) a. zheping jiu zui de [Zhangsan zhan-bu-qilai]

this wine drunk ACQ Zhangsan stand-not-up

'This bottle of wine got Zhangsan so drunk that he couldn't stand up.'

\footnotetext{
${ }_{10}$ We should add at this juncture that ACQ in SEA languages has developed many new features that are not attested in either Middle or Modern Chinese. See Enfield (2003) for a discussion of such innovations.
} 


\section{b. zhejian shi jidong de [Zhangsan shuo-bu-chu hua lai] this event excited ACQ Zhangsan speak-not-out words come 'This event got Zhangsan so excited that he couldn't speak a word.'}

Based on the similarities we have been discussing between ACQ in languages and that in Middle Chinese, we believe that it is highly plausible that they are essentially the same in morphological properties, and should thus be treated accordingly.

Summing up, ACQ in Chinese underwent three stages in the evolution of its morpho-syntactic properties. In Old Chinese, it could only be used preverbally, as a content word as well as a deontic and alethic modal. In Early Middle Chinese, while still keeping its basic lexical meaning, ACQ began to develop an array of functions that are typically ascribed to a grammatical morpheme, and its word order shifted from predominantly preverbal to postverbal. Crucially, its alethic modality is associated only with a postverbal position. Nonetheless, it exhibited a certain degree of positional freedom, allowing either a " $\mathrm{V}+\mathrm{ACQ}+\mathrm{O}$ " or a " $\mathrm{V}+\mathrm{O}$ + ACQ" order. From Late Middle Chinese till present, it continued to move along the grammaticalization cline until it behaves very much as a standard affix, with an almost completely bleached semantic content and a heavily weakened phonology. In a somewhat separate development, Middle Chinese ACQ found its way to SEA languages via language contact, thereby exhibiting greater similarities with the element of Middle Chinese than with that of Mandarin Chinese.

The facts discussed thus far shed light on the morphological properties of ACQ, and constitute strong evidence for the proposed lowering account. As can be seen, the alethic modal of ACQ indeed experienced a shift from a preverbal to a postverbal position, which in turn consists of two types: a cliticization-like process, which allows for a relatively free word order in Middle Chinese as well as in SEA languages, and an affixation-like process, which permits only rigid attachment to a verbal element in Mandarin Chinese.

One problem, however, poses some threat to our account. That is, lowering is generally conceived of as an operation on clitics and affixes, which are generally regarded as phonologically deficient morphemes. ACQ in SEA languages does not entirely fit the description. Examples in (14) and (15) show that in SEA languages, though not in Mandarin Chinese, ACQ can be used alone in answering simple questions, a sign of its phonological independence.

Despite this apparent problem, we still hold that the lowering account represents a plausible solution to ACQ under investigation, for the following reasons. In the first place, the present account adopts Boskovic's (2002) syntactic definition of clitics. Since ACQ is unmistakably a nonbranching element, i.e., an ambiguous $\mathrm{X}^{0} / \mathrm{XP}$, it may be viewed as a clitic irrespective of its phonological realizations. Note that it could be used alone in Middle Chinese as well, shown by instance such as (44). Nonetheless, its status as a clitic is rarely, if ever, questioned in literature. Furthermore, a crucial fact that one has to bear in mind is that ACQ is 
external for SEA languages, a calqued element and an instance of so-called contactinduced grammaticalization, ${ }^{11}$ rather than one that follows an internally directed process of grammaticalization with attritions in both semantics and phonology, as is true of ACQ in Mandarin Chinese. It is in fact a general consensus among researchers of language contact that a replicated linguistic item normally bears only partial resemblance to its source, and some adaptations are expected. Let us therefore assume that at the time when ACQ found its way to SEA languages, it was already so grammaticalized that its word order had become postverbal, as we have abundantly demonstrated in the foregoing discussion. Its phonetic features, on the other hand, received certain degree of adaptation in order for it to better incorporate into the system. Such a scenario is in fact precisely what is predicted in the multi-modular approach to language change and language contact. If this conjecture is plausible, the lowering operation can be viewed as detached from the actual phonological realizations of ACQ in SEA languages.

That the lowering operation may be detached from the phonetic feature of the object is actually allowed in Embick and Noyer's (2001) theory, according to which lowering takes place prior to Vocabulary Insertion, where the phonetic features are inserted. As such, lowering is more sensitive to the morpho-syntactic features of the target node than its phonological features.

As a matter fact, while there is no denying that ACQ in SEA languages is not as bound as a typical clitic, it does show certain degree of phonological dependency as compared to free morphemes. For instance, in Thai, dai is not normally used alone, apart from answering simple questions. On other occasions, it is more likely to co-occur with its host, typically a verbal element or a negation marker, as a single phonological word. Thus, it cannot be displaced, conjoined, or contrasted. The displacement case is shown below.

(46) a. khaw khian dai

he write ACQ

'He can write.'

b. *dai, khaw khian

ACQ, he write

'He can write.'

Pen is another postverbal modal in Thai with roughly the same range of meaning as dai. The next instances show that these two modals cannot be conjoined, nor contrasted.

(47) a. *khaw khian pen le dai

he write can and

'He can write.'

11 See Heine and Kuteva (2003, 2005); Matthews and Yip (2009), among others. 


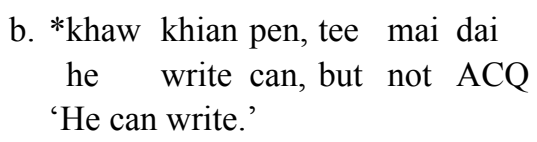

These instances show that dai in Thai, and by extension, ACQ in other SEA languages, does have traits of a clitic (see Zwicky 1985, among others).

Based on the discussion above, we believe it is conceptually viable to identify ACQ in SEA languages, and for that matter, ACQ in Middle Chinese as well, as essentially the same. To avoid a possible misunderstanding, we choose to stay on the safe side and designate ACQ in SEA languages a quasi-clitic, to capture the fact it has all the known properties of a clitic except for a restricted range of phonetic behavior due to adaptation in its new linguistic environments. In other words, ACQ in these languages is a clitic in disguise, since it behaves the same way as a clitic in grammatical function and word order, though not necessarily in phonological properties. Such an assumption is not entirely new if we treat it as essentially the same element as ACQ in Middle Chinese, which is recognized as a clitic, implicitly in traditional grammar where it is categorized under the umbrella term jiegouzhuci 'auxiliary word of structure', and explicitly in some recent work (see, for instance, Xu 2012, Bai et. al. 2012, Yang 2013).

To summarize, from a lexical word meaning "to acquire, to obtain," ACQ underwent an incremental process of grammaticalization, which ultimately yielded two types of functional morphemes. In the first, it is a quasi-clitic, as in the case of SEA languages, and in the second, it is very much an affix, as in the case of Mandarin Chinese. A quasi-clitic differs from an affix in that the former has greater positional freedom and is less choosy about its host, capable of adjoining onto a phrase, whereas the latter is more restricted as to where and to what it attaches. It is typically adjoined to a syntactic head with similar syntactic properties (see Spencer 1991 among others).

\section{Comparing the two accounts}

In the last two sections, we introduced Simpson's raising account and went on to propose an alternative lowering account. Since on both accounts, ACQ is base-generated in a preverbal position, we derive some basic empirical facts along similar lines, including, first, the placement of the negation marker prior to ACQ instead of prior to the main verb, and second, the obligatory use of ACQ in responding to a yes-no question. Note that in other accounts, these two properties are either not dealt with at all, or addressed in an ad hoc manner. By contrast, the solution provided in our accounts is more principled.

On the other hand, we differ from Simpson in salient and systematic ways since we make use of different movement operations based on different assumptions. In what follows, we shall identify some of the major differences and comment on merits and liabilities in each of the two accounts. 


\subsection{Movement-related issues}

The most obvious difference between the two accounts lies of course in the movement operations themselves. Recall that in Simpson's (2001) raising account, the predicate raises to some higher position so that it gets defocused while some element carrying new information, either dai itself, or the object of VP, gets the focus at the clause-final position. By contrast, on our morphological lowering account, ACQ lowers down to end up inside the VP in the postsyntactic stage, adjoining either to $\mathrm{V}$, as in Mandarin Chinese, or attaching to the VP, as the dominant sequence in most SEA languages.

We believe that the lowering account has several advantages over the raising one. The first advantage is of course that the former is a unified account of ACQ in Chinese and SEA languages, by treating them as basically the same element and deriving them with essentially the same morphological operation, while relegating their differences to a degree of grammaticalization, with ACQ in Mandarin Chinese as an affix and that in SEA languages as a quasi-clitic. Such a treatment dovetails with DM's abandonment of the modular distinction between affixes and clitics, with the former arranged by syntax and the latter via lexical rules. On the contrary, as pointed out by Embick and Noyer (2001: 560), DM takes affixes and clitics just as descriptive terms for bound morphemes with heterogeneous derivational histories. Simpson's raising account, however, does not offer any prospects of such unification, for Chinese does not focus its clause-final position, which in turn renders any predicate raising account unformulable. Given the agreed assumption that ACQ in Chinese and SEA languages is of the same origin, it goes without saying that a unified account is more desirable.

Another empirical advantage that the lowering account has over the raising account is that it better mirrors the grammaticalization process of ACQ. In our account, we take ACQ as the genesis of movement, which starts above VP and ends up after the verb via the application of the lowering operation. While we do not aim at an exact correspondence with diachronic development of the element, we do consider it evidence that ACQ indeed went through the process of changing from a preverbal position to a postverbal position, as amply demonstrated in the previous section. Clearly, mapping this historical path to a static picture, we can conclude that this change in linear structure reflects a process of lowering. By contrast, there is no historical evidence suggesting predicate raising, either for ACQ in Chinese, or that in SEA languages.

Conceptually, an advantage that our account has over the raising one is that it accords better with the movement theory in the more recent minimalist program (Chomsky 1995b, 1998, 2001). Recall that on our account, ACQ lowers in order to eliminate its own defective morpho-phonological features. Such movement is obviously motivated for self-interest. By contrast, Simpson argues that the predicate moves for the purpose of defocusing itself so that some other element gets focused. Such an altruistic movement is incompatible with ideas postulated in MP, which 
has consistently insisted on the thesis that movement be motivated for self-interest rather than to serve an altruistic purpose, be it the greed principle (Chomsky 1993, 1995b) or the enlightened self-interest principle (Lasnik 2005; Hornstein 2001) as proposed in the early days of MP, or the more recent Agree (Chomsky 2001, 2008). We therefore take Simpson's proposed motivation for movement as out of line with the MP framework.

Yet another aspect of the lowering account is more in keeping with the minimalist spirit, which associates crosslinguistic variation only with lexical properties of functional categories (Ouhalla 1991, Chomsky 1995b). For instance, Tang (1998) cogently argues that semantic features are invariant across languages, and that only features that may play a role in the derivation from numeration to the $\mathrm{PF}$ interface level including phonetic features, categorial features, and affix features are subject to parametric variation. In this respect, the morphological lowering account, which is based on the idiosyncratic morphological features of ACQ itself aligns better with the more recent minimalist framework than the light predicate raising account, which relies heavily on the semantic/discoursal features of focus, which are widely considered as invariant, incapable of triggering cross-linguistic variations.

Finally, cross-linguistic evidence seems to favor a lowering account. Take the distribution of adverbials as an example. In Thai, Lao, Vietnamese and other SEA languages, when there is an adverbial in the sentence, it, rather than ACQ, occurs in the clause-final position, as in the following sentences:

(48) a. khaw phuut phassa thai dai nit-nooi.

he speak language Thai ACQ a-little

'He can speak a little Thai.'

b. khao vao phasa lao dai nith-noy.

he speak language Lao ACQ a-little

'He can speak a little Lao.'

Such a phenomenon parallels that of determiner phrases in Bulgarian, as discussed in Embick and Noyer (2001, Section 5.1). In this language, a clitical definite article $-t a$ attaches to a nominal, or to an adjective that modifies the nominal, illustrated below (their example (20)):

(49) a. kniga-ta

book-DEF

'the book'

b. xubava-ta kniga

nice-DEF book

'the nice book'

By contrast, as shown in the next example (their (23)), an adverbial may not host Def (50a), or block lowering (50b): 
(50)
a. *mnog-ət star teatər
very-DEF old theater
'the very old theater'
b. mnogo starij-ə teatər
very old-DEF theater
'the very old theater'

Embick and Noyer account for the contrast by assuming that lowering operates at the level of category, which skips intervening adverbs. Their account can be naturally extended to instances such as (48).

The distribution of adverbials in SEA languages, however, poses a challenge to the raising analysis in that, if the predicate raises into a higher position, why does the VP-internal adverbial stay behind? This is undoubtedly a hard question for Simpson to answer.

\subsection{The status of ACQ and crosslinguistic variations}

In addition to the types of movement operations, there is another crucial difference between Simpson's light predicate raising and our morphological lowering. That is, Simpson takes dai in Thai as an independent modal verb, and extends the conclusion to the variants of ACQ in other languages. We reject this analysis and instead identify ACQ as an affix/quasi-clitic. Such a different view on the status of ACQ brings about a suite of different predictions, especially in the realm of cross-linguistic variations. In the rest of this section, we discuss two of these predictions: one relates to word order, and the other to the (in-) ability for ACQ to be used alone.

First, variations in word order. As discussed in Section 1, Mandarin Chinese and many other languages heavily influenced by Mandarin allow only the sequence "V + ACQ + O," whereas in SEA languages, the commonly-used sequence is "V + $\mathrm{O}+\mathrm{ACQ}$," while "V+ ACQ + O" is also acceptable though less frequent and more restricted in application.

We believe that such a word order difference comes from the idiosyncratic properties of ACQ, as is implicit in the foregoing discussion. On the one hand, ACQ in Mandarin and other Sinitic languages is relatively high on the grammaticalization cline, so it exhibits a greater degree of affix-like properties and adjoins exclusively to the verb. On the other hand, ACQ in Thai and other SEA languages, being less grammaticalized, is relatively free in position, and can either attach to the verb or to the object. We believe that such a conception allows a principled account of the cross-linguistic difference in the surface orders of ACQ.

Dialectal variations in Chinese provide supporting evidence for the blurry boundary between affix and clitic, and the accompanying variation in word order. In some dialects of Modern Chinese, a relatively free order of alethic ACQ can be 
observed, similar to that observed in the data from SEA languages, as shown by the following examples. ${ }^{12}$

(51) Kaihua (a sub-dialect of the Wu Dialects) (Cao et. al. 2000)
a. wo chui de qu guo.
I fight ACQ him over
'I can win over him in fight.'
b. wo chui qu de guo.
I fight him ACQ over
'I can win over him in fight.'

(52) Xiuning (a sub-dialect of the Hui Dialects) (Hirata 1997)
a. Lao-Wang jiang de guo xiao-li.
Mr. Wang argue ACQ over Mr. Li
'Mr. Wang can win over Mr. Li in debate.'
b. Lao-Wang jiang xiao-li de guo.
Mr. Wang argue Mr. Li ACQ over
'Mr. Wang can win over Mr. Li in debate.'

Simpson (2001), however, explains the two types of word order on the basis of information structure, on whether a FocP is present in the syntactic structure. To put it differently but equivalently, for this variation, he assumes (a) two structures, with a FocP as the complement of ACQ in "V + ACQ + O", but not in "V + O + ACQ" (see 25 and 26), and (b) two derivations, with "V+O + ACQ" derived via a single movement operation by which VP raises to the specifier of a certain phrase (XP) (see 25), and "V + ACQ + O" via two operations: first the movement of the object to the specifier of the FocP, and then the rest of the predicate to a preverbal position, in the specifier of what Simpson notates as YP.

We admit that in some languages such as Thai, the two sequences, "V + ACQ $+\mathrm{O}$ " and "V + O + ACQ," are indeed associated with a difference in information structure. Nevertheless, we consider this the result of some pragmatic/discoursal factor rather than a structural one. It is common knowledge that expressions in the clause-final position frequently convey new information, a phenomenon known as "end focus" (see, for instance, Zhuang 2014 and references therein). However, this fact does not suggest a structural difference. On the contrary, we believe that Simpson's theory faces a number of serious, sometimes insurmountable, problems. The first problem is that it is at odds with theories of historical linguistics. Recall Simpson's assumption that the variants of ACQ have a common ancestor. If so, it has never been attested that a single element can develop into two drastically different structures, with two entirely different derivational histories as well, as his

\footnotetext{
12 Examples of (51)-(52) are romanized in Hanyu Pinyin.
} 
account entails. According to the established view in typological studies, a content element can only evolve along two trajectories, either to become functionalized, or to be reanalyzed with an adjacent element. We believe that ACQ should not be an exception to this general pattern. In other words, ACQ is likely to become a functional element either as an affix or as a clitic, as proposed in our account, but is impossible to develop into an element with two structures and two derivational processes, as in Simpson's account.

The second problem associated with the proposed focus phrase relates to its position in the clausal structure. In Simpson's system, it is below DeP and above VP, so that the object is allowed in a clause-final position. However, it is generally accepted that (see, for instance, Radford 2009) the focus phrase has scope over the whole sentence, and is base-generated at the left edge above TP, and is one of the layers in the fine structure of sentences, along with the force phrase and the topic phrase ${ }^{13}$. Therefore, put in a broader context, the FocP Simpson proposes is positioned too low in the structure, and is too specific to ACQ sentences.

Yet another problem with the proposed focus phrase involves cross-linguistic variation, in that the clause-final object does not always have a focus meaning. For instance, the clause-final object in Mandarin Chinese is normally not focused. Instead, it gets focused only if preposed to a preverbal position, a scenario shown with the contrasting pair below.
a. ta pa de guo na-zuo shan.
he climb ACQ over that-CL mount
'He can climb over that mount.'
b. ta lian na-zuo shandou dou pa de guo. he even that-CL mount all climb ACQ over
'He can climb over even that mount.'
(unfocused)
(focused)

Simpson himself is aware of the difficulty of linking the clause-final position with focus. He shows that in Cantonese, an indefinite and non-specific NP, which is in no way focused, can take a clause-final position, as shown in (22). Simpson dismisses such a piece of counter-evidence by suggesting a mysterious loss of its original motivation. We find such an argument invalid, given that it is a general pattern in all Sinitic languages, rather than Cantonese alone, that a clause-final NP receives no focus at all.

The second area where cross-linguistic variation is observed is whether ACQ can be used alone. As can be seen in examples (14) and (15), relevant parts of which are reproduced below for the readers' convenience, ACQ must appear in conjunction with the main verb and some other auxiliary element in Chinese, but can either be used alone or together with the verb in Thai.

\footnotetext{
13 Hierarchically, ForceP, TopP and FocP are arranged as: ForceP $<$ TopP $<$ FocP.
} 
(14) Q: Zhe ge dongxini na de dong ma?

(Chinese)

This CL thing you take ACQ move Q

'Can you move this thing?'
$\mathrm{A} 1 \mathrm{Na}$ de dong.
take ACQ move
A2: *na/dong.
A3: *de.
'I can.'
take/move
ACQ

(15) Q: khaw phuut phasaa thai dai mai?

(Thai)

he speak language Thai ACQ Q?

'Can he speak Thai?'
A1: phuut dai.
speak ACQ
A2: *phuut.
A3: dai.
'He can.'
speak
ACQ

In our system, this cross-linguistic difference is again attributed to a difference in ACQ's morphological properties. As we argued in Section 4.3, ACQ in Mandarin Chinese is an affix and highly reduced phonologically, therefore unable be used alone. ACQ in SEA languages like Thai, however, is a quasi-clitic, thus less grammaticalized than its cognate in Mandarin Chinese; moreover, being a replicated element, its phonological features are adapted in the new linguistic environments, therefore capable of standing alone under restricted circumstances. By contrast, the raising account seems to have no way of explaining the variation.

\subsection{The co-occurrence of ACQ with another modal}

It was mentioned in Section 1 that ACQ may co-occur with a preverbal modal. On appearance, Simpson's light predicate raising and our morphological lowering accounts do equally well in this aspect, since we both allow different modals to take different syntactic positions, thus capable of appearing in the same clause. However, a closer look reveals that the lowering account, but not the raising account, may potentially provide plausible answers to a question that was posed in Section 1. That is, of all the modal meanings, why is ACQ associated only with alethic? This fact is actually predicted by our account, since we assume the alethic modal to be structurally the lowest of all the modals that make it the closest to VP, in accordance with Cinque's (199) universal hierarchy of functional heads as stated in (2). Recall that morphological lowering observes relativized minimality in the reverse order (see Section 4), ACQ's lowering is thus not blocked by an element of a similar kind. Epistemic and deontic modals, however, are more difficult to lower to a position inside VP, due to their higher structural positions and the workings of locality conditions.

Summing up, both raising and lowering accounts predict the possible cooccurrence of ACQ with another modal, by assuming different structural positions for different modals. However, the lowering account, but not the raising account, correctly predicts that ACQ can only be associated with alethic instead of epistemic or deontic meaning, due to the workings of locality conditions. 


\section{Conclusion}

In the foregoing sections, we proposed a morphological lowering account for alethic ACQ in both Chinese and SEA languages. We believe the relevant facts receive a natural and principled explanation if we adopt the DM architecture of grammar, which takes morphology as a series of operations at a post-syntactic stage for meeting requirements at the PF interface. Therefore, ACQ, which is base-generated at the preverbal $\mathrm{Al}($ ethic) node, lowers down to a postverbal position for morphological reasons. We compared and contrasted our lowering account with Simpson's (2001) raising account and demonstrated with ample evidence that our account is superior on both conceptual and empirical grounds. The lowering account provides a more plausible motivation for the movement operation, mirrors better the grammaticalization process of ACQ, and handles better the distribution of adverbials. Moreover, the lowering account is free from the problems and difficulties suffered by the raising account with respect to crosslinguistic variation, such as (a) drastically different structures and derivations for different surface orders, (b) problems associated with the proposed focus phrase, and (c) the inability to predict when ACQ can be used alone. Finally, the lowering account, but not the raising account, correctly predicts that ACQ is associated with alethic rather than epistemic and deontic meanings.

If the present account is on the right track, it sheds some light on how grammar is organized and how an optimal grammatical theory may be achieved. As implicit in the foregoing discussions, the most fundamental difference between the raising account and the lowering account is that the former adopts a purely syntactic approach whereas the latter is based on the cooperation and division of labor between syntax and morphology. The present study suggests that, while it is true that syntax is the primary builder of structures in human language, it is nonetheless unlikely to be the only one. Morphological operations may modify structures and strings assembled in the syntactic component, sometimes leading to form-meaning mismatches. As such, full consideration should be given to the contributions from the morphological component as well as the syntactic component when dealing with a specific element and its associated construction(s), such as alethic ACQ in Chinese and SEA languages.

\section{References}

Bai, Ge, Danqing Liu, Fang Wang \& Yanjun Fan. 2012. Beijinghua daici "ren" de qianfuzhuihua. [The encliticization of the pronoun "ren" in Beijing speech]. Yuyan Kexue [Linguistic Sciences], 11(4). 377-384.

Bisang, Walter. 1996. Areal typology and grammaticalization: Processes of grammaticalization based on nouns and verbs in East and mainland Southeast Asian languages. Studies in Language 20(3). 519-597.

Boskovic, Zeljko. 2002. Clitics as nonbranching elements and the linear correspondence axiom. Linguistic Inquiry 33. 329-340. 
Cao, Zhiyun, Akitani Hiroyuki, Ota Itsuku \& Rixin Zhao. 2000. A study of Chuqu subdialect in Wu dialect. Tokyo: Kohbun Syuppan.

Chomsky, Noam. 1993. A minimalist program for linguistic theory. In Kenneth Hale \& Samuel J. Keyser (eds.), The View from Building 20: Essays in linguistics in honor of Sylvain Bromberger, 1-52. Cambridge, MA: MIT Press. [Reprinted in Chomsky (1995b), 167-217.]

Chomsky, Noam. 1995a. Bare phrase structure. In Gert Webelhuth (ed.), Government and binding theory and the minimalist program, 383-439. Oxford: Blackwell.

Chomsky, Noam. 1995b. The minimalist program. Cambridge, MA: MIT Press.

Chomsky, Noam. 2001. Derivation by phase. In Michael Kenstowicz (ed.), Ken Hale: A life in language, 1-52. Cambridge, MA: MIT Press.

Chomsky, Noam. 2008. On phases. In Robert Freidin, Carlos Otero \& Maria L. Zubizarreta (eds.), Foundational issues in linguistic theory: Essays in honor of Jean-Roger Vergnaud, 133-166. Cambridge, MA: MIT Press.

Cinque, Guglielmo. 1999. Adverbs and functional heads: A cross-linguistic perspective. New York/Oxford: Oxford University Press.

Dong, Tonghe (Tung T'ung-ho). 1960. Hanyu yinyunxue [Chinese phonology]. Taiwan: Guangwen Shuju.

Embick, David \& Rolf Noyer. 2001. Movement operations after syntax. Linguistic Inquiry, 32(4), 555-595.

Embick, David \& Rolf Noyer. 2007. Distributed morphology and the syntax/ morphology interface. In Gillian Ramchand \& Charles Reiss (eds.), The Oxford handbook of linguistic interfaces, 289-324. Oxford: Oxford University Press.

Enfield, Nicholas J. 2001. On genetic and areal linguistics in mainland South-East Asia: Parallel polyfunctionality of "acquire." In Alexandra Y. Aikhenvald \& R. M. W. Dixon (eds.), Areal diffusion and genetic inheritance: Problems in comparative linguistics, 255-290. Oxford: Oxford University Press.

Enfield, Nicholas J. 2003. Linguistic epidemiology: Semantics and grammar in Mainland South-east Asia. London: Routledge.

Enfield, Nicholas J. 2004. Verbs and multi-verb sequences in Lao. In Anthony Diller, Jerry Edmondson \& Yongxian Luo. (eds.), Tai-Kadai languages. London: Routledge.

Halle, Morris \& Alec Marantz. 1993. Distributed morphology and the pieces of inflection. In Kenneth Hale \& Samuel J. Keyser (eds.), The View from Building 20: Essays in linguistics in honor of Sylvain Bromberger, 111-176. Cambridge: MIT Press.

Halle, Morris \& Alec Marantz. 1994. Some key features of distributed morphology. In Andrew Carnie \& Heidi Harley (eds.), MIT working papers in linguistics 21: Papers on phonology and morphology, 275-288. Cambridge: MIT Working Papers in Linguistics.

Heine, Bernd \& Tania Kuteva. 2003. On contact-induced grammaticalization. Studies in Language 27. 529-72.

Hirata, Shoji. 1997. Xiuning fangyan de dongci weiyuju [Sentences with verbal predicates in Xiuning dialect of Hui Dialect] in Li Rulong \& Zhang Shuang-qing 
(eds.), Dongci Weiyu Ju [Sentences with verbal predicates]. Guangdong: Jinan University Press.

Hopper, Paul. J. \& Elizabeth C. Traugott. 1993. Grammaticalization: Cambridge textbooks in linguistics. Cambridge: Cambridge University Press.

Hornstein, Nobert. 2001. Move! A minimalist theory of construal. Oxford: Blackwell. Huang, James. 1988. Wo paode kuai and Chinese phrase structure. Language 64(2). 274-311.

Huang, Bairong \& Xudong Liao. 1991. Xiandai hanyu [Modern Chinese]. Beijing: Gaodeng Jiaoyu Chubanshe [Higher Education Press].

Lasnik, Howard. 2005. Minimalist investigations in linguistic theory. London: Routledge.

Matthews, Stephen \& Virginia Yip. 2009. Contact-induced grammaticalization: Evidence from bilingual acquisition. Studies in Language 33(2), 366-395.

Myler, Neil. 2009. Linearization and post-syntactic operations in the Quechua DP. Cambridge Occasional Papers in Linguistics 5. 46-66.

Ouhalla, Jamal. 1991. Functional categories and parametric variation. London: Routledge.

Pollock, Jean-Yves. 1989. Verb movement, universal grammar and the structure of IP. Linguistic Inquiry 20(3). 365-424.

Radford, Andrew. 2009. An introduction to English sentence structure. New York: Cambridge University Press.

Rizzi, Luigi. 1990. Relativized minimality. Cambridge, MA: MIT Press.

Simpson, Andrew. 2001. Focus, presupposition and light predicate raising in East and Southeast Asia. Journal of East Asian Linguistics 10(2). 89-128.

Sybesma, Rint. 2008. Zhuang: A Tai language with some Sinitic characteristics. In Pieter Muysken (ed.), From linguistic areas to areal linguistics. 221-274. Amsterdam/Philadelphia: John Benjamins.

Tang, Sze-Wing. 1998. Parametrization of features in syntax. University of California at Irvine doctoral dissertation.

Wu, Fuxiang. 2002a. Hanyu nengxing shubu jiegou " $V$ de/bu $C$ " de yufahua [The grammaticalization of the alethic verb-complement construction " $\mathrm{V} \mathrm{de/bu} \mathrm{C"} \mathrm{in}$ Chinese]. Zhongguo Yuwen [Chinese Language] 1. 29-40.

Wu, Fuxiang. 2002b. Nengxing shubu jiegou suoyi [A tentative study on the alethic verb-complement construction]. Yuyan Jiaoxue Yu Yanjiu [Language Teaching and Research] 5. 19-27.

Wu, Fuxiang. 2003. Nanfang fangyan nengxing shubu jiegou " $V$ de/bu $C$ " dai binyu de yuxu leixing [Types of word order of the alethic verb-complement construction "V de/bu C" in Southern Chinese dialects]. Fangyan [Dialects] 3. 243-254.

Wu, Fuxiang. 2009. Cong “de”-yidong ci dao buzuyu biaoji-dongnanya yuyan de yizhong yufahua quyu [From the verb meaning 'get, acquire' to the resultative construction marker: A kind of grammaticalization area in the Southeast Asian languages]. Zhongguo Yuwen [Chinese Language] 3. 195-211.

$\mathrm{Xu}$, Jie. 2012. Cizui shao dan yuzui duo-hanyu yufa tedian de chongxin gaikuo [Less affixes, but more clitics-revisiting Chinese grammatical features]. Huazhong 
Shifan Daxue Xuebao (Renwen Sheke Ban) [Journal of Huazhong Normal University (Humanities and Social Sciences)] 2. 113-118.

Yang, Ping. 1989. "Dongci + de + binyu” jiegou de chansheng he fazhan [On the origin and development of the structure "verb + de + object"]. Zhongguo Yuwen [Chinese Language] 2.

Yang, Yanhua. 2013. Cizui, Yuzui yu xiandai hanyu yufa tixi [Affixes, clitics and the grammatical system of modern Chinese]. Huazhong Normal University doctoral dissertation.

Yue, Junfa. 1984. Deziju de chansheng he bianhua [On the origin and evolution of sentences with De]. Yuyan Yanjiu [Studies in language and linguistics] 2. 10-30.

Zhuang, Huibin. 2014. The prosodic history of Chinese resultatives. Language and Linguistics 15(4). 575-595.

\section{Gong Cheng}

Address: School of International Studies, Zhejiang University

No. 866, Yuhangtang Road

Hangzhou, Zhejiang Province, 310058, China

Email: $\quad$ chenggong@zju.edu.cn

Zhaohui Yi

Address: Department of Asian Languages, Luoyang University of Foreign

Languages

Luoyang, Henan, 471003, China

Email: yizhaohui@aliyun.com

Jianguo Xiong

Address: Department of Language Engineering, Luoyang University of Foreign Languages Luoyang, Henan, 471003, China

Email: jianguoxiong@126.com

Received: May 22, 2015

Accepted: December 30, 2015 


\title{
提升還是下降？一漢語及東南亞語言中能性“得”義語素研究
}

\author{
程工 $^{1}$ 、易朝暉 ${ }^{2}$ 、熊建國 ${ }^{3}$ \\ 浙江大學 $^{1}$ 、洛陽外國語學院亞洲語言系 ${ }^{2}$ 、 \\ 洛陽外國語學院語言工程系 ${ }^{3}$
}

\section{提要}

本文基於分佈式形態學理論, 為漢語及東南亞諸語言中表示能性情態的 “得” 義語 素提出形態下降分析法。該分析法認為 “得” 義語素基礎生成於動詞前的情態位置, 爾後在句法後音系式 (PF) 分支的推導過程中下降至動詞後位置。通過對比提升分析 法, 我們發現下降分析法無論是在理論上, 還是在對語言事實的解釋上都要略勝一 籌。

\section{關鍵詞}

能性 “得”，分佈式形態學，下降，提升，東南亞語言 